Received: 2017.04.05 Accepted: 2017.05.30 Published: 2017.08.22

\title{
Rhabdomyolysis in a Patient with Severe Hypothyroidism
}

Authors' Contribution:

Study Design A

Data Collection B

Statistical Analysis C

Data Interpretation D

Manuscript Preparation E

Literature Search $F$

Funds Collection $G$
ABCDEF 1 Nooshin Salehi

ABCDEF 2 Endre Agoston

ABCDEF 1 Iqbal Munir

ABCDEF 1,2 Gary J. Thompson
1 Department of Medicine, Riverside University Health System, Moreno Valley, CA, U.SA.

2 Department of Medicine, Loma Linda University Medical Center, Loma Linda, CA, U.S.A.
Corresponding Author: Conflict of interest:
Gary J. Thompson, e-mail: g.thompson@ruhealth.org None declared

\begin{tabular}{|c|c|}
\hline Patient: & Female, 52 \\
\hline Final Diagnosis: & Hypothyroidism induced rhabdomyolysis \\
\hline Symptoms: & Bilateral leg pain • fatigue \\
\hline Medication: & Levothyroxine $•$ Calcitriol • Calcium Gluconate \\
\hline Clinical Procedure: & - \\
\hline Specialty: & Endocrinology and Metabolic \\
\hline Objective: & Unusual clinical course \\
\hline Background: & $\begin{array}{l}\text { Muscular symptoms, including stiffness, myalgia, cramps, and fatigue, are present in the majority of the pa- } \\
\text { tients with symptomatic hypothyroidism, but rhabdomyolysis, the rapid breakdown of skeletal muscle, is a rare } \\
\text { manifestation. In most patients with hypothyroidism who develop rhabdomyolysis, precipitating factors, such } \\
\text { as strenuous exercise or use of lipid-lowering drugs, can be identified. }\end{array}$ \\
\hline Case Report: & $\begin{array}{l}\text { We report a case of a 52-year-old Hispanic woman with a history of hypothyroidism, hypertension, and type } 2 \\
\text { diabetes mellitus who presented with fatigue, severe generalized weakness, bilateral leg pain, and recurrent } \\
\text { falls. She reported poor medication compliance for the preceding month. Initial laboratory testing showed ele- } \\
\text { vated thyroid stimulating hormone (TSH) and creatine kinase (CK) levels, indicating uncontrolled hypothyroid- } \\
\text { ism with associated rhabdomyolysis. Supportive treatment with intravenous fluids and intravenous levothy- } \\
\text { roxine were initiated and resulted in dramatic clinical improvement. }\end{array}$ \\
\hline Conclusions: & $\begin{array}{l}\text { We report a case of rhabdomyolysis, which is a rare but potentially serious complication of hypothyroidism. } \\
\text { Screening for hypothyroidism in patients with elevated muscle enzymes should be considered, since an early di- } \\
\text { agnosis and prompt treatment of hypothyroidism is essential to prevent rhabdomyolysis and its consequences. }\end{array}$ \\
\hline
\end{tabular}

MeSH Keywords: Hypocalcemia $\bullet$ Hypokalemia $\bullet$ Hypothyroidism • Methadone $\bullet$ Rhabdomyolysis • Trimethoprim-Sulfamethoxazole Combination

Full-text PDF: https://www.amjcaserep.com/abstract/index/idArt/904691 


\section{Background}

According to the National Health and Nutrition Examination Survey (NHANES) [1], hypothyroidism is found in $4.6 \%$ of the U.S. population, with $0.3 \%$ presenting clinically and $4.3 \%$ being subclinical [1]. Clinical signs and symptoms of hypothyroidism are often nonspecific, but muscular symptoms, including stiffness, myalgia, cramps, and fatigue are described by the majority of patients with clinical hypothyroidism [2] In patients with hypothyroidism, muscle enzymes may be elevated [2], but usually at levels less than ten times the upper limit of normal [3]. However, rhabdomyolysis, the rapid breakdown of skeletal muscle, due to hypothyroidism is rare $[2,4]$ and in most of the reported cases, a precipitating factor has been identified, such as the use of lipid-lowering drugs [5-9], or strenuous exercise $[10,11]$. Rhabdomyolysis due to hypothyroidism, without an obvious precipitating factor, has been previously reported in the literature, but is very rare [3,12-19]. We describe a case of a 52-year-old woman with a known diagnosis of hypothyroidism and poor medication compliance, who presented with a new onset rhabdomyolysis.

\section{Case Report}

A 52-year-old Hispanic woman with a past medical history of type 2 diabetes mellitus, hypertension, chronic hepatitis $C$, hypothyroidism, osteoarthritis, and opiate dependence presented to the emergency department with a three-day history of severe bilateral leg pain. She stated that she had run out of her medications about one month before presentation. She complained of fatigue, generalized weakness, headache, nausea, decreased appetite, numbness in her fingers, dry skin, and constipation for the few weeks before presentation, and she also reported dysuria and decreased urination for the preceding three days. She denied chest pain, shortness of breath, vomiting, or diarrhea, but had several recent falls that were not associated with syncope or major injury.

The patient was diagnosed with hyperthyroidism (Graves disease) in childhood and underwent subtotal thyroidectomy when she was 12 years old. She had been on levothyroxine, calcium, and vitamin D supplements since her thyroidectomy. She was also diagnosed with type 2 diabetes mellitus three years previously. The patient reported poor compliance with her home medications and glucose monitoring. She had completed a ten-day course of trimethoprim-sulfamethoxazole for a reported urinary tract infection a week before admission.

The patient had been smoking cigarettes, approximately onequarter pack a day for the past 15 years, but did not drink alcohol. She had a history of heroin dependence, and was on methadone, as prescribed by her ambulatory methadone clinic.
Her medications included aspirin $81 \mathrm{mg}$ od, Metformin 1,000 mg bid, glipizide $10 \mathrm{mg}$ od, atenolol $50 \mathrm{mg}$ od, levothyroxine $100 \mathrm{mcg}$ od, calcium gluconate $650 \mathrm{mg}$ od, cholecalciferol 5,000 IU/day, methadone $60 \mathrm{mg}$ od, gabapentin 200-400 mg/day, as needed, and Naprosyn $200 \mathrm{mg}$ bid, as needed.

In the emergency department, physical examination showed elevated blood pressure of $186 / 105 \mathrm{mmHg}$, body temperature of $36.4^{\circ} \mathrm{C}$, respiratory rate of $16 / \mathrm{min}$, and heart rate of $76 / \mathrm{min}$. Her weight was $122.2 \mathrm{~kg}$ with a body mass index (BMI) of $52.6 \mathrm{~kg} / \mathrm{m}^{2}$.

On admission, the patient was noted to be confused and lethargic, but responded to voice commands. She was noted to have a deep, hoarse voice, bilateral peri-orbital edema, and bilateral exophthalmos. Mucous membranes were dry, and her tongue was normal. The abdomen was morbidly obese. Non-pitting edema in the bilateral upper and lower extremities was present, and several patchy areas of ecchymosis were present on the upper extremities. Physical examination was otherwise unremarkable.

Laboratory data (Table 1) showed findings suggestive of hypothyroidism, hypocalcemia, and mild hypokalemia. The patient also had an elevated creatine kinase (CK) of 5,814 IU/L, which supported the clinical diagnosis of rhabdomyolysis. Urinalysis was normal. Electrocardiogram and chest X-ray were unremarkable.

Her elevated blood pressure improved after the administration of metoprolol $50 \mathrm{mg}$ orally, and improved pain control was achieved with the administration of hydrocodone and acetaminophen $10 \mathrm{mg}$ and $325 \mathrm{mg}$ orally, respectively. She was treated with intravenous (IV) fluids and IV calcium gluconate. The patient was given a total of 1.5 liters of normal saline. The patient was also treated with levothyroxine $200 \mathrm{mcg}$ IV daily for three consecutive days and then transitioned to oral levothyroxine $125 \mathrm{mcg} /$ day. Vitamin D was supplemented with oral calcitriol. Echocardiography showed moderate concentric left ventricular hypertrophy with normal ejection fraction (60-65\%) and no pericardial effusion. Potassium was replaced with IV and then oral potassium chloride. Once appropriate therapy was initiated, the presenting symptoms improved significantly over the next several days, and by day 5, the CK level decreased to 2,349 IU/L. The patient was discharged home with instructions to continue her clinical follow-up with her primary care physician within two weeks.

\section{Discussion}

Hypothyroidism is characterized by a broad spectrum of clinical findings, including muscular symptoms, but hypothyroid myopathy is most often limited to myalgia, muscle stiffness, and cramps, and occasionally associated with mildly elevated levels of muscle enzymes [20]. 
Table 1. Laboratory data.

\begin{tabular}{|c|c|c|c|c|c|c|c|}
\hline Variable & Reference range & Day 1 & Day 2 & Day 3 & Day 4 & Day 5 & Day 6 \\
\hline Glucose, random (mg/dL) & 74-106 & 207 & 211 & 249 & 211 & 138 & 153 \\
\hline HgbA1c (\%) & $4.2-6.3$ & & 9.6 & & & & \\
\hline Serum sodium (mEq/L) & $136-145$ & 138 & 140 & 139 & 138 & 140 & 142 \\
\hline Serum potassium (mEq/L) & $3.6-5.0$ & 3.5 & 3.0 & 3.6 & 3.4 & 3.2 & 3.8 \\
\hline Anion Gap (mmol/L) & $5.0-14.0$ & 7 & 10 & 9 & 10 & 10 & 9 \\
\hline BUN (mg/dL) & $7-18$ & 16 & 14 & 13 & 15 & 15 & 24 \\
\hline Serum creatinine $(\mathrm{mg} / \mathrm{dL})$ & $0.55-1.02$ & 1.5 & 1.44 & 1.56 & 1.59 & 1.51 & 1.62 \\
\hline Calcium (mg/dL) & $8.5-10.4$ & 6.1 & 5.7 & 6.1 & 6.5 & 7.7 & 8.2 \\
\hline Phosphorus (mg/dL) & $2.5-4.9$ & & 4.6 & 4.6 & 5.4 & & \\
\hline Parathyroid hormone $(\mathrm{pg} / \mathrm{mL})$ & $14-64$ & & 2 & & & & \\
\hline Magnesium (mEq/L) & $1.8-2.4$ & & 2.0 & 2.4 & 2.1 & & \\
\hline Albumin, serum (g/dL) & $3.4-5.0$ & 3.5 & 2.8 & 3.2 & 3.0 & 3.1 & 3.4 \\
\hline Alkaline phosphatase (U/L) & $45-117$ & 112 & 88 & 105 & 97 & 101 & 102 \\
\hline Alanine aminotransferase (U/L) & $12-78$ & 40 & 34 & 38 & 31 & 30 & 30 \\
\hline Aspartate aminotransferase $(\mathrm{U} / \mathrm{L})$ & $15-37$ & 71 & 60 & 61 & 45 & 37 & 38 \\
\hline Total bilirubin (mg/dL) & $0.2-1.0$ & 0.8 & 0.5 & 0.5 & 0.4 & 0.6 & 0.7 \\
\hline Thyroid stimulating hormone (mIU/L) & $0.36-3.74$ & 74.0 & & & & & \\
\hline Thyroxine (T4), free (ng/dL) & $0.76-1.46$ & 0.20 & & & & & \\
\hline Triiodothyronine (T3), total (ng/dL) & $76-181$ & & 37 & & & & \\
\hline Creatine kinase (IU/L) & 22-198 & 5814 & & 4657 & & 2349 & \\
\hline Troponin I (POCT) & Titer & $<0.05$ & & & & & \\
\hline Total Cholesterol (mg/dL) & $0-200$ & & & & & 219 & \\
\hline High-density lipoprotein (mg/dL) & $40-60$ & & & & & 35 & \\
\hline Low-density lipoprotein (mg/dL) & $0-100$ & & & & & 152 & \\
\hline Triglyceride (mg/dL) & $30-150$ & & & & & 295 & \\
\hline AM Cortisol (mcg/dL) & $4.0-22.0$ & & & & & 32.1 & \\
\hline Total 25-hydroxy vitamin $\mathrm{D}(\mathrm{ng} / \mathrm{mL})$ & $30-100$ & & 34 & & & & \\
\hline Hemoglobin (g/dL) & $12-15.3$ & 11.8 & 11.3 & & & & \\
\hline
\end{tabular}

Day 1 is the first day of admission at our hospital. The symptoms of rhabdomyolysis commenced three days before Day 1 .

Rhabdomyolysis is characterized by skeletal muscle necrosis and release of intracellular muscle constituents into the circulation [21]. Some of the known causes of rhabdomyolysis include vigorous exercise, inflammatory myopathies (polymyositis), congenital deficiency of muscular enzymes, trauma, infection, electrolyte disorders (hyponatremia, hypokalemia, hypocalcemia), hyperosmolar states, medications including statins, and toxins, including alcohol [3].
Rhabdomyolysis, the rapid breakdown of skeletal muscle, may also develop due to hypothyroidism [2-10,18,22]. Myolysis in hypothyroidism is caused by changes in muscle fibers from fast-twitching type II to slow-twitching type-I fibers, deposition of glycosaminoglycan, poor contractility of actin-myosin units, low myosin ATPase activity, and low ATP turnover in the skeletal muscles [23]. With hypothyroidism, there is an inhibition of mitochondrial activity in muscle cells as well as dysregulation of many metabolic pathways such as Krebs cycle, fatty acid catabolism and glycolytic energy production [24]. These 
metabolic abnormalities may sensitize patients with hypothyroidism to develop rhabdomyolysis, especially in the presence of other factors that may provoke the development of myopathy.

The patient described in this case report had not taken her usual thyroid medication for about a month before admission, and showed both clinical and laboratory findings of hypothyroidism (Table 1). The patient presented with extreme fatigue, peri-orbital edema, non-pitting edema in the extremities, dry skin, constipation, as well as low free thyroxine (T4), high thyroid stimulating hormone (TSH), and hyperlipidemia. The diagnosis of rhabdomyolysis was based on the findings of severe myalgia, muscle weakness, and marked elevation of creatinine kinase (CK) levels (a 30-fold elevation). Muscular symptoms with mild to moderate elevation in CK levels are common findings in patients with hypothyroidism [2,21], but only in a very small proportion of these patients will muscular involvement progress to the point of developing overt rhabdomyolysis $[2,4]$.

Most patients with hypothyroidism who develop rhabdomyolysis are found to have a clear precipitating risk factor, such as the use of lipid-lowering drugs [6-10] or strenuous exercise $[11,12]$, but none of these risk factors were present in this case. As this case has shown, rhabdomyolysis may also develop due to hypothyroidism alone [3,4,12-19], but this is rare. Rhabdomyolysis caused by severe hypothyroidism alone has also been reported in the pediatric age group [25]. Clinical awareness of this rare complication of hypothyroidism may modify clinical management and screening tests for hypothyroidism, for example, before starting statin therapy [5]. Also, hypothyroidism should be considered as a possible etiology in patients presenting with acute renal failure and elevated muscle enzymes after initiating statin therapy [5].

Review of the literature for hypothyroidism-induced rhabdomyolysis is summarized in Table 2. The differential diagnosis for the development of rhabdomyolysis, in this case, is also summarized as follows.

Hypokalemia: The patient presented with mild hypokalemia, with a serum potassium of $3.5 \mathrm{mEq} / \mathrm{L}$ (reference range: 3.6-5.0 $\mathrm{mEq} / \mathrm{L}$ ) on admission. After administration of IV fluids and subcutaneous insulin, the potassium level further declined to $3.0 \mathrm{mEq} / \mathrm{L}$, which prompted administration of IV potassium chloride. The serum potassium levels then improved to $3.6 \mathrm{mEq} / \mathrm{L}$, and fluctuated between $3.2-3.8 \mathrm{mEq} / \mathrm{L}$ (Table 1) in the following days.

Profound hypokalemia with serum potassium levels of less than $2.5 \mathrm{mEq} / \mathrm{L}$, may cause rhabdomyolysis by reducing blood flow to the muscles in response to exertion [21]. Hypokalemia is also associated with severe muscle weakness and pain in the setting of thyrotoxic periodic paralysis (TPP) [26], and in a reported case of TTP, myopathy progressed to the development of rhabdomyolysis [27]. In our case, the patient had only mild hypokalemia (Table 1). Therefore, it is unlikely that hypokalemia played a significant role in the development of rhabdomyolysis in this patient.

Hypocalcemia: The patient presented with a serum calcium of $6.1 \mathrm{mg} / \mathrm{dL}$ (normal range: 8.5-10.4). The corrected calcium level, given the low albumin in this case, was still low at 6.5 $\mathrm{mg} / \mathrm{dL}$. Hypocalcemia is associated with rhabdomyolysis, but is considered to be a result of rhabdomyolysis rather than a cause $[21,28,29]$. In a study on traumatic crush injuries, hypocalcemia was found in all the patients with rhabdomyolysis [30].

There have been several case reports in which hypocalcemia has been considered as the possible cause of rhabdomyolysis, but the mechanism of hypocalcemia-induced rhabdomyolysis is not well understood [31-33]. In a case report by Akmal [31], he reports a case of rhabdomyolysis in a patient with hypoparathyroidism whose calcium was as low as $4.1 \mathrm{mg} / \mathrm{dL}$. In two other cases, reported by Hower et al. [32], the calcium levels were also as low as 4.4 and $3.8 \mathrm{mg} / \mathrm{dL}$. In another case of hypoparathyroidism presenting with rhabdomyolysis, reported by Sumnu et al., the serum calcium level was $3.7 \mathrm{mg} / \mathrm{dL}$ [33]. According to this review of the literature, the corrected calcium level of $6.5 \mathrm{mg} / \mathrm{dL}$, as shown in our patient, was unlikely to have been the cause of rhabdomyolysis.

Mechanical injury: The patient reported several uncomplicated falls before admission. Although mechanical injury is reported to cause elevated CK levels, most rhabdomyolysis cases are related to crush injuries [21]. We believe that the history of falls in this patient was probably related to her fatigue and generalized weakness due to her untreated hypothyroidism.

Methadone: There are a few published case reports of rhabdomyolysis following methadone use $[34,35]$. It has been proposed that methadone may increase muscle demand for oxygen, and subsequently augment the state of muscle ischemia [35]. The patient was not taking methadone in the last few days before her presentation to the hospital. After admission, methadone was restarted with the dose of $30 \mathrm{mg}$ a day, but rhabdomyolysis continued to improve with the treatment of her hypothyroidism despite methadone use.

Trimethoprim-sulfamethoxazole: There have been several reports of trimethoprim-sulfamethoxazole-induced rhabdomyolysis in immunocompromised patients [36-39], but it seems to be very rare in the immunocompetent patients. To our knowledge, only two cases of trimethoprim-sulfamethoxazole-induced rhabdomyolysis have been reported in immunocompetent patients $[40,41]$. 
Table 2. Findings of a literature review on hypothyroidism-induced rhabdomyolysis.

\begin{tabular}{|c|c|c|c|c|c|c|c|}
\hline Title of the Article & Authorship & $\begin{array}{c}\text { Year of } \\
\text { publication }\end{array}$ & $\begin{array}{l}\text { Age, } \\
\text { gender }\end{array}$ & $\begin{array}{l}\text { Status of thyroid } \\
\text { disease }\end{array}$ & $\begin{array}{l}\text { Reported risk } \\
\text { factors }\end{array}$ & $\begin{array}{c}\text { TSH } \\
\text { mIU/L }\end{array}$ & $\begin{array}{l}\text { CK } \\
\text { IU/L }\end{array}$ \\
\hline $\begin{array}{l}\text { Hypothyroidism } \\
\text { as a cause of } \\
\text { rhabdomyolysis }\end{array}$ & Barahona et al. & 2002 & 49 , male & Undiagnosed & None & 147.7 & 9,332 \\
\hline $\begin{array}{l}\text { Rhabdomyolysis and } \\
\text { renal failure in } \\
\text { hypothyroidism }\end{array}$ & Halverson et al. & 1976 & 60 , female & $\begin{array}{l}\text { Hypothyroid, } \\
\text { diagnosed } 7 \\
\text { years prior }\end{array}$ & None & $>100$ & 5,400 \\
\hline $\begin{array}{l}\text { Rhabdomyolysis due } \\
\text { to hypothyroidism }\end{array}$ & Altay, et al. & 2005 & 31 , male & Undiagnosed & None & $>100$ & 2,291 \\
\hline $\begin{array}{l}\text { Massive pericardial } \\
\text { effusion and } \\
\text { rhabdomyolysis } \\
\text { secondary to } \\
\text { untreated severe } \\
\text { hypothyroidism: the } \\
\text { first report }\end{array}$ & $\begin{array}{l}\text { Zare-Khormizi } \\
\text { et al. }\end{array}$ & 2014 & 27, male & $\begin{array}{l}\text { Hypothyroid, } \\
\text { diagnosed } 10 \\
\text { years prior }\end{array}$ & None & 237 & 5,600 \\
\hline $\begin{array}{l}\text { Rhabdomyolysis } \\
\text { case based on } \\
\text { hypothyroidism }\end{array}$ & Katipoglu et al. & 2016 & 53 , male & Thyroidectomy & None & 43.2 & 1,560 \\
\hline $\begin{array}{l}\text { Rhabdomyolysis } \\
\text { in a patient with } \\
\text { hypothyroidism }\end{array}$ & Kisakol et al. & 2003 & 19, male & Undiagnosed & None & 148 & 10,210 \\
\hline $\begin{array}{l}\text { Acute myoedema: an } \\
\text { unusual presenting } \\
\text { manifestation of } \\
\text { hypothyroid myopathy }\end{array}$ & Bhansali et al. & 1999 & 41 , male & $\begin{array}{l}\text { Hypothyroid, } \\
\text { diagnosed } 6 \\
\text { years prior }\end{array}$ & hyponatremia & 58.9 & 80,730 \\
\hline $\begin{array}{l}\text { Hashimoto's } \\
\text { thyroiditis presenting } \\
\text { as Hoffman's } \\
\text { syndrome, } \\
\text { rhabdomyolysis and } \\
\text { acute kidney injury }\end{array}$ & Ahmed et al. & 2014 & 33 , male & Undiagnosed & $\begin{array}{l}\text { Moderate } \\
\text { alcohol } \\
\text { consumption, } \\
\text { tick bite }\end{array}$ & 209 & 2,333 \\
\hline $\begin{array}{l}\text { Rhabdomyolysis } \\
\text { and acute renal } \\
\text { impairment in } \\
\text { a patient with } \\
\text { hypothyroidism: a } \\
\text { case report }\end{array}$ & Naz et al. & 2014 & 33, male & Undiagnosed & $\begin{array}{l}\text { Strenuous } \\
\text { physical } \\
\text { activity }\end{array}$ & 145.7 & 7,200 \\
\hline $\begin{array}{l}\text { Hypothyroidism } \\
\text { induced severe } \\
\text { rhabdomyolysis in a } \\
\text { hemodialysis patient }\end{array}$ & Tatar et al. & 2014 & 56 , female & $\begin{array}{l}\text { Subclinical } \\
\text { hyperthyroidism } \\
\text { on } \\
\text { propylthiouracil }\end{array}$ & Hemodialysis & $>100$ & 6,314 \\
\hline
\end{tabular}

In our patient, severe hypothyroidism was likely the principal etiology of rhabdomyolysis. It is also possible that patients with hypothyroidism have increased susceptibility to developing rhabdomyolysis. The presence of other risk factors for rhabdomyolysis, including the well-known risk factors such as strenuous exercise and statin use, or weakly associated risk factors, such as methadone use, may help to precipitate rhabdomyolysis.
In a literature review of ten previously reported cases of hypothyroidism-induced rhabdomyolysis (Table 2), only four cases had a known pre-existing diagnosis of hypothyroidism when they presented with rhabdomyolysis. One reported case had a previous diagnosis of subclinical hyperthyroidism and was taking propylthiouracil. In the five remaining cases, thyroid disease was not previously diagnosed. In this review, 
hypothyroidism-induced rhabdomyolysis appeared to be more common in males (80\%), despite hypothyroidism being more common in women. In six of the cases, no precipitating risk factors for rhabdomyolysis were reported (Table 2).

Clinicians should be aware of the potential risk of hypothyroidism-induced rhabdomyolysis, as further investigation of other precipitating risk factors could be beneficial. By identifying these risk factors, clinicians can avoid, for example, the use of statins or trimethoprim-sulfamethoxazole that may predispose patients with hypothyroidism to the development of rhabdomyolysis.

Muscular symptoms are mentioned by the majority of the patients with frank hypothyroidism and can be the predominant or the only clinical manifestation of hypothyroidism [2]. According to the clinical guidelines of American Thyroid Association [42], finding an elevated serum concentration of one or both of the muscle enzymes, CK and lactic dehydrogenase (LDH), that persist for at least two weeks, is enough to justify the request of serum TSH assay in order to confirm or exclude hypothyroidism [42].

Furthermore, healthcare provider awareness of rhabdomyolysis as a rare complication of hypothyroidism, and exploration

\section{References:}

1. Hollowell JG, Staehling NW, Flanders WD et al: Serum TSH, T4, and thyroid antibodies in the United States population (1988 to 1994): National Health and Nutrition Examination Survey (NHANES III). J Clin Endocrinol Metab, 2002; 87: 489-99

2. Sindoni A, Rodolico C, Pappalardo MA et al: Hypothyroid myopathy: A peculiar clinical presentation of thyroid failure. Review of the literature. Rev Endocr Metab Disord, 2016; 17(4): 499-519

3. Barahona MJ, Mauri A, Sucunza $\mathrm{N}$ et al: Hypothyroidism as a cause of rhabdomyolysis. Endocr J, 2002; 49: 621-23

4. Chowta MN, Chowta NK: Hypothyroidism-associated rhabdomyolysis. Indian J Med Sci, 2008; 62: 496-97

5. El-Hosseini A, Chemitiganti R, Burks J: Hypothyroidism and simvastatin as a combined cause of rhabdomyolysis acute renal failure. Am J Case Rep, 2010; 11: 7-9

6. Yeter E, Keles T, Durmaz T, Bozkurt E: Rhabdomyolysis due to the additive effect of statin therapy and hypothyroidism: A case report. J Med Case Rep, 2007; 1: 130

7. Ambapkar SN, Shetty N, Dwivedy A, Malve HO: Statin-induced rhabdomyolysis in patient with renal failure and underlying undiagnosed hypothyroidism. Indian J Crit Care Med, 2016; 20: 305-7

8. Jbara Y, Bricker D: Rhabdomyolysis in the setting of induced hypothyroidism and statin therapy: A case report. Eur Thyroid J, 2015; 4: 62-64

9. Chaudhary N, Duggal AK, Makhija P et al: Statin-induced bilateral foot drop in a case of hypothyroidism. Ann Indian Acad Neurol, 2015; 18: 331-34

10. Sekine N, Yamamoto M, Michikawa M et al: Rhabdomyolysis and acute renal failure in a patient with hypothyroidism. Intern Med, 1993; 32: 269-71

11. Naz A, Issa M: Rhabdomyolysis and acute renal impairment in a patient with hypothyroidism: A case report. Case Rep Med, 2014; 2014: 139170

12. Bhansali A, Chandran V, Ramesh J et al: Acute myoedema: An unusual presenting manifestation of hypothyroid myopathy. Postgrad Med J, 2000; 76: 99-100

13. Halverson PB, Kozin F, Ryan LM, Sulaiman AR: Rhabdomyolysis and renal failure in hypothyroidism. Ann Intern Med, 1979; 91: 57-58 of other possible risk factors of rhabdomyolysis may help provide a more timely diagnosis and treatment for these patients. Hypothyroidism is a common and usually easily treatable disease, but learning more about its different manifestations and complications can significantly improve the care of patients, and deserves consideration.

\section{Conclusions}

This case report describes a patient suffering from rhabdomyolysis related to severe hypothyroidism. Rhabdomyolysis is a rare but potentially life-threatening complication of hypothyroidism that can occur in patients with poor medication compliance, as illustrated by our case report. Therefore, early diagnosis and appropriate treatment of hypothyroidism are essential. Screening for hypothyroidism in patients with elevated muscle enzymes, as recommended by the American Thyroid Association [42], may detect pre-existing subclinical hypothyroidism and subsequently lead to more timely treatment of hypothyroidism and prevention of its complications.

\section{Conflicts of interest}

None.

14. Jain S, Bhargava K, Sawlani KK et al: Myoglobinuria and transient acute renal failure in a patient revealing hypothyroidism. J Assoc Physicians India, 1999; 47: 444-46

15. Katipoglu B, Ates I, Acehan F et al: Rhabdomyolysis case based on hypothyroidism. Endocrinol Diabetes Metab Case Rep, 2016; 2016: pii: 16-0083

16. Ahmed GS, Zaid HM, Moloney M: Hashimoto's thyroiditis presenting as Hoffman's syndrome, rhabdomyolysis and acute kidney injury. BMJ Case Rep, 2014; 2014: pii: bcr2013203269

17. Zare-Khormizi MR, Rahmanian M, Pourrajab F, Akbarnia S: Massive pericardial effusion and rhabdomyolysis secondary to untreated severe hypothyroidism: The first report. Acta Clin Belg, 2014; 69: 375-78

18. Kisakol G, Tunc R, Kaya A: Rhabdomyolysis in a patient with hypothyroidism. Endocr J, 2003; 50: 221-23

19. Altay M, Duranay M, Ceri M: Rhabdomyolysis due to hypothyroidism. Nephrol Dial Transplant, 2005; 20: 847-48

20. Leonetti F, Dussol B, Berland Y: Rhabdomyolysis and kidney failure in hypothyroidism. Presse Med, 1992; 21: 31-32

21. Singhal PC, Kumar A, Desroches $L$ et al: Prevalence and predictors of rhabdomyolysis in patients with hypophosphatemia. Am J Med 1992; 92: 458-64

22. Tatar E, Isikyakar T, Yeniay KP: Hypothyroidism induced severe rhabdomyolysis in a hemodialysis patient. Case Rep Med, 2014; 2014: 501890

23. Wiles CM, Young A, Jones DA, Edwards RH: Muscle relaxation rate, fibretype composition and energy turnover in hyper- and hypo-thyroid patients. Clin Sci (Lond), 1979; 57: 375-84

24. Thompson PD, Clarkson P, Karas RH: Statin-associated myopathy. JAMA, 2003; 289: 1681-90

25. Marzuillo P, Grandone A, Perrotta S et al: Very early onset of autoimmune thyroiditis in a toddler with severe hypothyroidism presentation: A case report. Ital J Pediatr, 2016; 42: 61

26. Hsiao YH, Fang YW, Leu JG, Tsai MH: Hypokalemic paralysis complicated by concurrent hyperthyroidism and hyperaldosternoism: A case report. Am Case Rep, 2017; 18: 12-16 
27. Chang KY, Lee SH, Park HS et al: Severe hypokalemia and thyrotoxic paralysis from painless thyroiditis complicated by life-threatening polymorphic ventricular tachycardia and rhabdomyolysis. Intern Med, 2014; 53: 1805-8

28. Llach F, Felsenfeld AJ, Haussler MR: The pathophysiology of altered calcium metabolism in rhabdomyolysis-induced acute renal failure. Interactions of parathyroid hormone, 25-hydroxycholecalciferol, and 1,25-dihydroxycholecalciferol. N Engl J Med, 1981; 305: 117-23

29. Ishikawa T, Inagaki H, Kanayama M, Manzai T: Hypocalcemic hyper-CK-emia in hypoparathyroidism. Brain Dev, 1990; 12: 249-52

30. Safari S, Eshaghzade M, Najafi I et al: Trends of serum electrolyte changes in crush syndrome patients of Bam earthquake; A cross sectional study. Emerg (Tehran), 2017; 5: e7

31. Akmal M: Rhabdomyolysis in a patient with hypocalcemia due to hypoparathyroidism. Am J Nephrol, 1993; 13: 61-63

32. Hower J, Struck H, Tackmann W, Bohlmann HG: Myopathy and elevated serum enzymes in a case of hypoparathyroidism. Z Kinderheilkd, 1974; 116: 193-96

33. Sumnu A, Aydin Z, Gursu M et al: A case of primary hypoparathyroidism presenting with acute kidney injury secondary to rhabdomyolysis. Case Rep Nephrol, 2016; 2016: 3240131

34. Valga-Amado F, Monzón-Vázquez TR, Hadad F et al: Rhabdomyolysis with acute renal failure secondary to taking methadone. Nefrologia, 2012; 32 262-63
35. Hojs R, Sinkovic A: Rhabdomyolysis and acute renal failure following methadone abuse. Nephron, 1992; 62: 362

36. Jen SP, Sharma R: Trimethoprim-sulphamethoxazole-associated rhabdomyolysis in an HIV-infected patient. Int J STD AIDS, 2011; 22: 411-12

37. Kiel PJ, Dickmeyer N, Schwartz JE: Trimethoprim-sulfamethoxazole-induced rhabdomyolysis in an allogeneic stem cell transplant patient. Transpl Infect Dis, 2010; 12: 451-54

38. Anders HJ, Bogner JR, Goebel FD: Mild rhabdomyolysis after high-dose trimethoprim-sulfamethoxazole in a patient with HIV infection. Eur J Med Res, 1997; 2: 198-200

39. Walker S, Norwood J, Thornton C, Schaberg D: Trimethoprim-sulfamethoxazole associated rhabdomyolysis in a patient with AIDS: Case report and review of the literature. Am J Med Sci, 2006; 331: 339-41

40. Ainapurapu B, Kanakadandi UB: Trimethoprim-sulfamethoxazole induced rhabdomyolysis. Am J Ther, 2014; 21: 78-79

41. Mancano MA: Trimethoprim-sulfamethoxazole-induced rhabdomyolysis Gabapentin-induced hypoglycemia in diabetic and nondiabetic patients Purple glove syndrome after oral phenytoin administration; Acute dystonic reaction after methylphenidate initiation; Serotonin syndrome with vilazodone monotherapy; Cabozantinib-associated dermatologic adverse reactions. Hosp Pharm, 2015; 50: 662-66

42. Ladenson PW, Singer PA, Ain KB et al: American Thyroid Association guidelines for detection of thyroid dysfunction. Arch Intern Med, 2000; 160: 1573-75 